From the American

Board of Family Medicine

Ann Fam Med 2021;19:89-90. https://doi.org/10.1370/afm.2661.

\section{EMPOWERING FAMILY PHYSICIANS TO DRIVE CHANGE IN PRACTICE: PLANS FOR THE ABFM NATIONAL JOURNAL CLUB}

Often lost in an age of health system consolidation, population health, and big data, is the importance of single clinical decisions, made one patient at a time by family physicians working with their patients. Yet it is these decisions, made over time and in the context of a trusting doctor-patient relationship, that are key to robust primary care and to addressing the Triple Aim. Family physicians are the most numerous and widely distributed personal physicians, and it is important to support them in this role and to help them keep up to date. ABFM steps into this breach on behalf of our Diplomates, their patients, and communities.

The primary long-term goal of the ABFM National Journal Club is to improve the competence performance of practicing family physicians and to support their ongoing professional development. Although clinical practice guidelines, point-of-care services (eg, UpToDate and Essential Evidence Plus), and predigested evidence-based reviews of the literature (eg, ACP Journal Club and Journal Watch) function as essential first steps in practicing evidence-based medicine, mastery of the art of applying evidence to patient care requires a greater depth of understanding of the evidence. ABFM aims to foster this by curating the selection of the most important articles for family physicians, providing the full-length article, inviting critical appraisal of the articles and discussion of implications for practice. The ABFM believes such a depth of understanding is vital for Diplomates when acting in their capacity as a personal physician and individualizing the application of current evidence to the patient sitting across from them in the exam room. Shared decision making depends on the ability to integrate and, if appropriate, move beyond population-based guidelines, article conclusions, or "expert" opinion to help patients decide on a care plan consistent with both medical science and each patient's own preferences, goals, and values.

To lead the development of the journal club, ABFM has recruited a National Journal Club Committee. The Committee was selected by ABFM from 41 family physicians nominated by the Council for Academic Family Medicine (ie, Association of Family Medicine Residency Directors [AFMRD], Association of Departments of Family Medicine [ADFM], North American Primary Care Research Network [NAPCRG], Society of Teachers of Family Medicine [STFM], and the American Academy of Family Physicians $[\mathrm{AAFP}])$. Committee members were selected on the basis of engagement in clinical practice and expertise in critical appraisal of the literature. The members of the committee are listed in Table 1 ; they represent a diversity of practice settings, geographic regions and career stages. They are deeply committed to improving care with evidence. The ABFM National Journal Club Committee will select articles for inclusion, write assessment questions and commentaries on articles, and drive ongoing evaluation and improvement of the program.

The design of the National Journal Club is modelled on Osler's original journal club. Each year, the National Journal Club will identify the top 100 most important articles for practicing family physicians. We will use an explicit 2-phase structured search. In the first phase, committee members will screen articles previously identified on the basis of methodology and value by EBM services InfoPOEM, ${ }^{2}$ Journal Watch, ${ }^{3}$
Table 1. ABFM National Journal Club Committee Members

\begin{tabular}{ll}
\hline Name & Practice Setting \\
\hline Leslie Brott, MD, FAAFP & Summit Medical Group \\
Steve Brown, MD, FAAFP & University of Arizona - College of Medicine \\
Valerie Gilchrist, MD & University of Wisconsin School of Medicine \\
Joel Heidelbaugh, MD, FAAFP, FACG & University of Michigan Medical School \\
Erik Lindbloom, MD, MSPH & University of Missouri \\
Corey Lyon, DO, FAAFP & University of Colorado School of Medicine \\
Anjali Mahoney, MD, MPH, FAAFP & University of Southern California, Los Angeles \\
Fred Miser, MD & Ohio State University \\
James Puffer, MD & University of California, Los Angeles \\
Kate Rowland, MD, MS & Rush Copley Family Medicine Residency Program \\
Dean Seehusen, MD, MPH & August University \\
Celeste Song, MD, MS & Highland Family Medicine \\
Joseph Lane Wilson, MD & Brody School of Medicine at Eastern Carolina University \\
Stephen Wilson, MD, MPH, FAAFP & Boston Medical Center \\
Jennifer Wipperman, MD, MPH & University of Kansas School of Medicine - Wichita \\
Jay Zimmerman, MD & Penn State Health - Milton S. Hershey Medical Center \\
\hline
\end{tabular}


and the ACP Journal Club, ${ }^{4}$ as well as those identified by other ABMS Certification Boards. Committee members will also nominate articles based on their own personal strategies for monitoring the medical literature, with future plans for all Diplomates to nominate articles as well. In the second phase, the committee will select the top 100 articles, using a systematic process to prioritize according to relevance to broad scope family medicine, methodological rigor, and potential to change practice.

Participation in the journal club will be optional for ABFM Diplomates and will not require payment beyond the annual certification process fee. After completing 20 article assessments in a single year, Diplomates will earn 10 certification points and meet the minimum Self-Assessment requirement for a 3-year stage. Each article assessment activity will require Diplomates to demonstrate mastery by correctly answering all questions for each article. Correct answers and rationales will be provided after their first attempt ${ }_{i}$ Diplomates will have the opportunity to retest until successful. We are also arranging with the AAFP to provide CME for each completed article assessment.

The ABFM Journal Club platform will include 8 web-based elements:

- Reading List: A listing of National Journal Article selections from which Diplomates will be able to select based on interest and/or relevance.

- Hook Question: A clinical vignette which sets the stage for the topic addressed by the article, followed by a practice assessment question which the Diplomate will be asked to answer. The intent of the hook question is to stimulate interest in the article.

- Peer Feedback: Graphic feedback will be provided to Diplomates comparing their answer to the hook question with all other participants.

- Article: A full-text copy of the article selected.

- Post-Article Assessment: Four multiple-choice questions will follow each article. Two questions will highlight a clinical/trial detail germane to the clinical interpretation. A third question will assess understanding of a methodological principle important for interpretation of the article. The fourth question will address applicability to clinical practice.

- Critiques: Correct answers to the question, including why answers are wrong, and a succinct description of the methodologic principle.

- Expert Discussion and Commentary: A discussion of the validity, relevance, and value of the article's findings and how it applies to clinical practice. The discussion will include an overview of how the article corroborates, contradicts, or advances what was previously known about the subject (and include references). The expert commentary will reflect clinical consensus reached by the committee, highlighting the "take-home" message from the article and including pertinent information for discussion with patients.

- Comments Section: A forum for Diplomates which is designed to share their thoughts and engage in a discussion regarding the clinical implications of the article.

A formal pilot will launch in the summer of 2021. Volunteers will be recruited from ABFM's 97,000 Diplomates. Their feedback will drive the evolution of the National Journal Club. Diplomates who participate in the activity will be able to read as many or as few articles as they choose. Supporting teaching evidencebased medicine in residencies is also important, both in teaching fundamentals of evidence-based medicine for residents, and also improving ongoing clinical care. We have begun discussions with both AFMRD and FPIN (Family Practice Information Network) to support curricular innovations.

In summary, the aim of the ABFM National Journal Club is to help family physicians keep up to date, to support shared decision making with patients and families, and to empower family physicians to advocate for their patients with subspecialists, health systems, and payers. ABFM's approach builds on that of other Certification Boards and seeks to advance the methodology of journal article activities with structured literature searches, emphasis on methodologic rigor, and a requirement of mastery.

It was the iconic American scientist and senior statesman, Ben Franklin, who said "Tell me and I forget, Teach me and I remember, Involve me and I learn." On behalf of the ABFM National Journal Club Committee, and on behalf of ABFM, we look forward to involving our Diplomates and our educational partners to build this new resource for the specialty.

Martin A. Quan, MD, David Geffen School of Medicine at

UCLA Clinical Family Medicine; Warren P. Newton, MD, MPH, American Board of Family Medicine, University of North Carolina School of Medicine Department of Family Medicine, Lara Handler, MSLS, American Board of Family Medicine; Emily Banik, PMP, American Board of Family Medicine

\section{References}

1. Quan MA, Newton WP. Helping family physicians keep up to date: a next step in the pursuit of mastery. J Am Board Fam Med. 2020;33(Supp):S24-S27.

2. Essential Evidence Plus. POEMs research summaries. Published 2020. Accessed Nov 14, 2020. https://www.essentialevidenceplus. com/content/poems

3. NEJM Journal Watch. Accessed Nov 14, 2020. https://www.jwatch. org/

4. ACP Journal Club. Accessed Nov 14, 2020. https://www.acponline. org/clinical-information/journals-publications/acp-journal-club 